\title{
Davidsonian Naturalism and "A-Ontological" Philosophy of Mind
}

John Fennell

\section{(2) OpenEdition}

\section{Journals}

Electronic version

URL: http://journals.openedition.org/ejpap/555

DOI: 10.4000/ejpap.555

ISSN: 2036-4091

\section{Publisher}

Associazione Pragma

Electronic reference

John Fennell, « Davidsonian Naturalism and "A-Ontological" Philosophy of Mind », European Journal of Pragmatism and American Philosophy [Online], V-2 | 2013, Online since 24 December 2013, connection on 04 May 2019. URL : http://journals.openedition.org/ejpap/555; DOI : 10.4000/ejpap.555

This text was automatically generated on 4 May 2019.

\section{(c) (i) (9)}

Author retains copyright and grants the European Journal of Pragmatism and American Philosophy right of first publication with the work simultaneously licensed under a Creative Commons AttributionNonCommercial-NoDerivatives 4.0 International License. 


\title{
Davidsonian Naturalism and "A- Ontological" Philosophy of Mind
}

\author{
John Fennell
}

1 In this paper I will argue that Davidson's position in the philosophy of mind undergoes a change from the early "Mental Events," where he emphasizes how it entails a physicalist ontological position, to his later writings, which ultimately suggest an "a-ontological," discursive-pluralist position. In this later position, instead of foregrounding the physicalist ontological consequences of anomalous monism, Davidson devalues the importance of the ontological significance of mental vocabulary and emphasizes instead the importance of the humanistic explanatory interests that are served and preserved by such vocabulary. I will also point out some collateral benefits of the later, a-ontological position - namely, that it defuses two common and supposedly telling criticisms of Davidson's anomalous monism, viz. that it is not really a form of (physical) monism, and that it is not importantly anomalous. However, before doing so, I spend some time explaining how this a-ontological position is achieved, which is through Davidson's particular form of naturalism. In order to characterize his naturalism, I distinguish two different senses of the term - anti-supernaturalism and non-normativism - and argue that Davidson is committed to the first but not the second. Doing so enables him to occupy a naturalistic position which holds that there is an irreducible normative-rational dimension to human beings and their meaning-bearing, understanding-embodying activities (e.g., speaking a language and having intentional mental states) without having to posit the existence of anything beyond the natural in order to account for it. While evident throughout his philosophy, I will concentrate on how this naturalism shows itself in his philosophy of mind, where it is signaled by the conceptual, as opposed to ontological, character of his distinction between the mental and the physical. To hold that the mental and the physical, or that reason and cause (and in the context of his philosophy of mind I will use these terminological pairs interchangeably as normativerational relations are constitutive of the mental and causal or law-like ones are constitutive of the physical for Davidson ${ }^{1}$ ), are conceptually as opposed to ontologically distinct is to hold that the mental/physical, or reason/cause (or law-like), distinction is a distinction not at the level of things or events themselves, but at the level of descriptions of 
things or events. That is, it involves holding that one can describe intentional phenomena in a way that situates them in the "space of reasons," i.e., as bearing rational relations to each other, without thereby requiring that these descriptions refer to reasons as separate ontological kinds, i.e., without rational descriptions hypostatizing reason into a kind of thing. In his philosophy of mind, this conceptual distinctness of the mental and the physical is expressed in his thesis of the anomalousness of the mental, and in his later writings I will show how this anomalousness of the mental gets expressed, in turn, as the "a-ontological-ness" of the mental. In the final section I discuss what the point of mental vocabulary is for later Davidson, given that it is not ontological, and argue that its value has a distinctly Kantian flavor.

\section{Two Kinds of Naturalism: Anti-Supernaturalism and Non-Normativism}

2 In order to get clear on just what kind of naturalism Davidson is committed to, it is important to distinguish two senses of naturalism. The first form of naturalism consists in the rejection of Meanings and Minds (with a capital "M") - i.e., meanings thought of as transcendent abstrata (à la Frege) and minds thought of as Cartesian immaterial substances categorically distinct from anything in physical nature. As Minds and Meanings understood in these ways are denizens of an extra- or super-natural domain of either Platonic or Cartesian character, naturalism in this form is naturalism qua antisuper-naturalism. The second form of naturalism amounts to the denial of any normative-rational dimension to human beings, and thus denies a normative-rational dimension to the central human activities of holding contentful mental states and speaking meaningful language. Naturalism in this second sense consists in reducing or eliminating ${ }^{2}$ the is/ought, fact/norm, cause (or law-like)/reason distinctions, and so this form of naturalism is naturalism qua non-normativism.

Unlike Quine who advocates both forms of naturalism, Davidson holds the first but not the second ${ }^{3}$ - for him, mind, meaning and reason are to be naturalized (desupernaturalized, de-transcendentalized) without being naturalistically reduced or eliminated. He does so by separating two issues that are typically run together: the issue of conceptual reduction (whether mental/intentional descriptions or concepts can be captured without loss in physical/causal (or law-like) descriptions and concepts) from the issue of ontological reduction (whether non-physical things or states, e.g., platonic-like abstractions or Cartesian mental substances, can be reduced to physical things or states). Separating these two reductions allows for the possibility that the lack of a conceptual reduction of mind and meaning does not entail that there is no ontological reduction, that it need not carry in its train a dualist commitment to entities beyond the natural world of spatiotemporal objects and events. ${ }^{4}$ This kind of naturalism is one in which mind and meaning are de-transcendentalized, i.e., are nothing over and above physical objects, events and the relations between them, without thereby being stripped of their normative-rational character. ${ }^{5}$

It is this kind of naturalism that Davidson subscribes to, and since it insists on the irreducibility or distinctness of the mental and the physical, of reason and cause (or the law-like), one needs to be clear on what this distinctness amounts to. By the expression "the distinctness of reason and cause (or the law-like)" one could mean that reasons 
cannot be causes (or law-like), or that causes (or what is law-like) cannot be reasons. This, though, is not what Davidson means by the phrase, indeed far from it - not only is his theory of action famously predicated on reasons being able to be causes and vice versa, ${ }^{6}$ his philosophy of mind identifies mental events with physical events at the ontological level. So, since reasons can be causes and vice versa, and mental states are to be identified with physical states, the distinctness of reason and cause is not an ontological distinctness. Rather the distinctness is conceptual; it is not that there are two distinct things or events that rational and causal (or law-like) descriptions and explanations respectively refer to, it is that one and the same things or events (contents) are susceptible to rational and causal (or law-like), mental and physical, descriptions and explanations. Though contents can be described in distinct ways, these descriptions can nevertheless be true of the same things - one does not have to posit different things as the bearers of the two descriptions, i.e., be committed to ontological dualism. The relation between rational and causal (or law-like) descriptions, then, is rather like the relation between the descriptions "the morning star" and "the evening star": rational descriptions are distinct from the causal (or law-like) ones but this does not necessarily mean that these distinct descriptions are true of different things, just as the distinctness of the descriptions of "the morning star" (viz. most visible celestial body in the sky in the morning) and "the evening star" (viz. most visible celestial body in the sky in the evening) does not require the existence of numerically distinct celestial bodies.

5 Thus, the conceptual nature of the distinctness between the mental and the physical dovetails with the form of naturalism I am attributing to Davidson here: that it does not require an ontological dualism supports the form of naturalism which embraces antisupernaturalism, but that it insists on the distinctness of mental and physical (or normative-rational and causal or law-like) descriptions means that it rejects nonnormativism. If normative-rational relations are conceptually distinct from causal or lawlike relations, and if they are constitutive of content-bearing states, then the normativerational dimension of these states (and meaning-bearing activities in general) can neither be eliminated nor reduced to causal or law-like relations. As such, the normative-rational dimension is not banished from the picture and naturalism qua non-normativism is resisted. However in being only conceptually distinct, normative rational relations and causal or law-like relations can well be ontologically compatible in the sense of referring to the same kinds of things or events, and so need not require positing anything supernatural to account for them. So naturalism qua anti-supernaturalism is embraced.

\section{The Distinctness (or Anomalousness) of the Mental}

6 In his philosophy of mind, the conceptual as opposed to ontological nature of the distinctness of the mental and the physical is signaled from the start, where the mental/ physical distinction is one that qualifies events-under-a-description rather than events themselves:

[A]n event is mental if and only if it has a mental description... physical events are those picked out by descriptions that contain only physical vocabulary. (Davidson 1970: 211)

7 That is, what makes an event a mental event is that it can be described in mental vocabulary, and what makes an event physical is that it can be described in physical vocabulary. And since all the mentally described events can bear physical descriptions as 
well, all events are physical (thus a weak kind of physicalism, token-identity physicalism, is entailed). However, the conceptual as opposed to ontological distinctness of the mental and the physical does not just follow from this initial, and admittedly problematic, suggestion about how to identify the mental and the physical; more importantly, it is essentially tied to a core commitment of Davidson's philosophy of mind: the anomalousness of the mental. Indeed, the conceptual distinctness of the mental and the physical is just another way of expressing the thesis of the anomalousness (or a nomological-ness) of the mental, the thesis that there are no strict laws, no strict general connections (whether in the form of type-identities or type-correlations) between mental kinds and physical kinds. ${ }^{8}$ What is ultimately responsible for this anomalousness is that the mental and the physical have different constitutive principles, more precisely, that normative-rational principles play a constitutive role in the identification and attribution of contentful mental states whereas they have no role to play whatever in the identification and attribution of physical states. Since the principles constitutive of mental states are different in kind (in being normative-rational ones) from the principles that are constitutive of physical states (in being descriptive-causal/law-like ones), the former cannot be inferred from the latter, e.g., as a result of being type-identified or typecorrelated (nomologically connected) with them. For, if there were such strict mentalphysical laws, then the presence of a type of physical state would be enough to attribute a (its nomologically correlated) type of mental state, but then since physical states constitutively bear out causal or law-like relations, which need not reflect normative rational ones, the mental state attributed on their basis would no longer be guaranteed to reflect normative-rational relations that it bears to other mental states already attributed, and thus normative-rational relations would no longer be constitutive of mental state attribution.

8 To illustrate: suppose there were strict laws connecting certain kinds of neural states ( $\mathrm{NS}_{1}$ and $\mathrm{NS}_{2}$ ) with beliefs of certain sorts - e.g., that if $\mathrm{NS}_{1}$ is present then one has the belief that $p$ and $q$, and that if $\mathrm{NS}_{2}$ is present then one has the belief that not- $p$. Now, if there were such laws and the relevant kinds of neural states were instantiated, one could attribute the belief that $p$ and $q$ and the belief that not- $p$. That is, if there were such strict psychophysical laws, one could attribute beliefs on the basis of the presence of certain kinds of physical states irrespective of whether attributing such beliefs abided by normative-rational relations, such as the inference rule of simplification (or conjunction elimination). In this way belief attribution would no longer be constitutively constrained by such normative-rational principles. Of course, it may so happen that a given attribution of a mental state on the basis of its law-like correlated physical state reflects the normative-rational relations that the state bears to other mental states already attributed (after all normative-rational relations may be mirrored in causal or law-like relations), but this would just be a happy happenstance; the mental state attributed would not have to be so correlated in order to be attributed in the first place. There would be no necessity that the attributed mental state did bear these normative-rational relations; it would be possible for it not to, and so the constitutiveness of normativerational relations to the mental would be sacrificed. Thus, argues Davidson, the distinctiveness of contentful states in constitutively bearing normative-rational relations to each other blocks the possibility of strict psychophysical laws. 


\section{Ontological Consequences of the Conceptual Distinctness of the Mental and the Physical}

What are the ontological implications of this conceptual distinctness of the mental and the physical? I think two very different, though formally compatible, answers emerge at different times in Davidson's work: a certain kind of weak physicalism - token-identity physicalism - which he emphasizes in his earlier work, and an "a-ontological" (or "postontological" to use the felicitous phrase of Ramberg, 2000) attitude, i.e., an indifference to ontological implications, that emerges in his later work. Both fall out of his separating conceptual reduction from ontological reduction, but each expresses a different reaction to, or attitude towards, this separation.

10 In his earlier work Davidson underlines that the conceptual as opposed to ontological nature of the distinction between mental and physical at once makes conceptual room for token-identity physicalism. It is a position that "shows how there could be identities without correlating laws" (Davidson, 1970: 213); a position that shows how one could be a physicalist, an identity theorist (each particular mental event, i.e., event described in mental terms, is one and the same as some particular physical event or other, i.e., event described in physical terms), without having to posit strict, generally applicable identities or correlations between kinds of mental events and kinds of physical events. Rather, this token-identity position can be characterized as follows: if one were to collect together all the particular physical events it is not as if there would be a whole other class of events over and above all these physical events that would have been left out, viz. the mental events (for qua things, they are identical with the physical things, only described in a different way). Thus, as Davidson sometimes puts it (Davidson, 1970: 214 and 1985: 243), mental events are nothing over and above physical events, ontologically they are (token-) identical to physical events, but this is not to say that the mental is nothing but the physical. ${ }^{9}$ So, the irreducibility of the mental to the physical does not entail ontological dualism. (Davidson's emphasis on this physicalist ontological implication in "Mental Events" was perhaps due to the state of philosophy of mind at the time. By the early 1970s, type-identity theories were coming under attack from the multiple-realizability objection, and one of the key questions that arose was whether these attacks on typereductionism undermined physicalist accounts of the mind generally. In this context, Davidson's view is prima facie exciting for physicalists since it opens up the possibility a version of physicalism without type-reduction, and so suggests that arguments against type-reduction need not undermine a physicalist account of the mind).

11 However a different attitude toward the ontological implications of his token-identity view emerges from later writings:

Let me first make clear that in my view the mental is not an ontological but a conceptual category... To say of an event, for example an intentional action, that it is mental is simply to say that we can describe it in a certain vocabulary - and the mark of that vocabulary is semantic intentionality. Reason-explanations differ from physical explanations because they are couched (in part) in an intentional vocabulary, and the basic concepts of this vocabulary cannot be reduced, or related by strict laws, to the vocabularies of the physical sciences. (Davidson, 1987: 114) Our mental concepts are as essential to our understanding of the world as any others and we could not do without them. To have or acquire a propositional attitude, such as an intention, desire, belief, hope, fear, is to have or acquire a 
property in as objective a sense as can be... How could there be a question about the ontology of mental entities for me if, as I hold, mental entities are identical with entities we also describe and explain, in different terms, in the natural sciences? (Davidson, 1999a: 595)

I agree with Rorty that "we are equally in touch with reality when we describe a hunk of space-time in atomic, molecular, cellular, physiological, behavioral, intentional, political, or religious terms." Hunks of space-time are real enough, so whatever we say about them, we are "in touch with reality," even if we describe some hunks as witches, griffons, or gods. But saying this does not eliminate differences, and I persist in thinking that the intensional idioms of psychology differ from the rest. The differences do not, I hope I have made clear, touch on ontology... What I have chiefly emphasized is the irreducibility of our mental concepts. They are irreducible in two senses. First, they cannot be defined in the vocabularies of the natural sciences, nor are there empirical laws linking them with physical phenomena in such a way as to make them disposable. Second, they are not an optional part of our conceptual resources. They're just as important and indispensable as our common-sense means of talking and thinking about phenomena in non-psychological ways... It is worth emphasizing the irreducibility of the mental but only because the irreducibility springs from something more interesting than the indeterminacy of translation and interpretation, degree of complexity, clarity, holism. What makes the difference is the constitutive role of normativity and rationality in psychological concepts, a role they do not play in the natural sciences. (Davidson, 1999a: 599)

[S]o far as my argument for anomalous monism is concerned that argument is an argument quite generally for monism, since it is designed to show that the ontology of any science that is not reducible to physics shares its ontology with physics.

(Davidson, 1999b: 619)

These passages emphasize, again, the separation of the issue of ontological reduction from the issue of conceptual reduction, but now a different inflection is put on this separation. This separation of ontological and conceptual issues, of course, ensures that the conceptual irreducibility of the mental to the physical does not entail any dualist ontological implications, but rather than highlighting that it makes possible physicalism at the ontological level, now he highlights that it downgrades the importance of ontological questions all together in the philosophy of mind (e.g. "The mental is not an ontological but a conceptual category," "How could there be a question about the ontology of mental entities for me?," "The differences [between the mental and the physical] do not touch on ontology," "So far as my argument for anomalous monism is concerned it is designed to show that the ontology of any science that is not reducible to physics shares its ontology with physics"). Here, Davidson is not so much a physicalist ontologically speaking, as a-ontological; he is not so much advocating a deflationist (i.e., anti-supernaturalist or physicalist) position in ontology, but a deflationist position about ontology. Rather than being reminded that the conceptual distinctness of the mental allows for a physicalist position in ontology, we are told that it does not "touch on ontology," and it does not because mental descriptions carry the same ontological commitments as physical descriptions - they just commit one to the existence of physical events. ${ }^{10}$ However the point now is that just because psychological vocabulary has no dualist ontological import, just because it "shares its ontology with physics," what is distinctive and important about mental vocabulary is not something that can be got at by looking to ontology. Or to put it another way, that mental vocabulary does not commit us ontologically to anything in addition to what physical vocabulary does does not show that it is retrograde and dispensable, rather what it shows, Davidson thinks, is that we should look elsewhere than ontology to find where its significance and indispensability lies. 

it can show how one can still be a physicalist ontologically speaking while holding onto the distinctness of the mental. Rather, it is that in showing that the mental's irreducibility to the physical does not require the positing of a different ontology from the physical, it in turn shows that what is significant about the irreducibility of the mental is not anything ontological. Precisely by separating conceptual from ontological reduction and thereby showing how "the ontology of any science that is not reducible to physics shares its ontology with physics," ontological issues get divested of their importance in determining whether, and what, is worth preserving about mental vocabulary. Instead of emphasizing the compatibility of his position with physicalism, as he did before, by reassuring us that the irreducibility of mental vocabulary does not entail ontological dualism, Davidson here emphasizes instead the relative insignificance of the compatibility of an irreducible and ineliminable mental vocabulary with a physicalist ontology. (This change in emphasis is, also, likely due to the historical context of philosophy of mind by the late-1990s. According to Davidson, the main danger that now needs to be resisted is the Quine-inspired eliminativism of the Churchlands and their followers, who precisely argued for the elimination of mental, or folk psychological, vocabulary on the grounds of its lack of ontological import, and consequently of its (supposed) falsity and explanatory bankruptcy. ${ }^{11}$ Although Davidson does not deny the lack of ontological import of mental vocabulary, by nevertheless insisting that it still has an indispensible explanatory role to play, he is, in effect, downgrading the importance of such ontological matters).

From this "a-ontological" perspective, Davidson has new strategies of response to each of the two main criticisms his anomalous monism has faced. Simply, critics see him caught in a dilemma: they argue that Davidson cannot have both his physicalism and his anomalism - he can either hold onto the anomalousness of the mental or the physicalism, but not both. The first decry the weakness of Davidson's position as a brand of physicalism charging that his version of physicalism, which embraces the anomalousness of the mental, is really just crypto-dualism (epiphenomenalism, to be precise) in disguise. This criticism is chiefly due to Kim (Kim, 1993: 20-21), who sees Davidson as ultimately defending the anomalism and sacrificing the physicalism. The second charge that the alleged anomalousness of the mental with respect to the physical is really no more profound or distinctive than, e.g., the anomalousness of the geological (or the chemical or the biological, etc.) with respect to the physical, and that just as these do not undermine a non-naïve nomological connection between the geological, chemical, biological, etc., and the physical, neither should the supposed anomalousness of the mental with respect to the physical. This criticism is chiefly due to Fodor (Fodor, 1987: 4-6 and 2000: 20f); and by putting the mental in nomological relation to the physical, it saves the physicalism of Davidson's view but at the expense of the anomalism. I will look at these criticisms in turn, and at Davidson's new "a-ontological" strategies of response to each.

Kim, in effect, charges that Davidson's token-identity physicalism is "token physicalism," a brand of physicalism so weak as to not deserve the title. In addition to stopping short of countenancing general identities or even correlations, the weakness of Davidson's tokenidentity position as a physicalist position is evident in his initial characterization of what makes an event mental or physical as simply being its ability to bear a mental or a physical description, ${ }^{12}$ as we noted earlier. Given this, of course Kim is right to point out that Davidson's position is a very weak form of physicalism, and looked at from the 
perspective of defending a physicalist position in ontology this is indeed a telling weakness. Later Davidson concedes this point, but suggests that to look at anomalous monism in this way (i.e., as primarily about defending a version of physicalism) is to miss the point, for he now intends it to express not a physicalist position in ontology but an aontological position. If using psychological vocabulary to describe a state does not entail different ontological commitments from using physical vocabulary to describe it, the moral Davidson now wants to draw is: this just shows that the point and significance of employing mental vocabulary is not ontological. In the past (Davidson, 1970: 214) Davidson leaned on the notion of supervenience to safeguard the claim that his anomalous monism was a robust (or robust-enough) form of physicalism, arguing that since the mental supervened on the physical, mental properties depended on, or were determined by, physical properties, and since this showed the reliance of the mental on the physical, he claimed it underwrote a "robust-enough" physicalism. Now he has changed tack: anomalous monism is not a form of dualism because of the conceptual (rather than ontological) nature of the mental-physical distinction, and while he concedes that the kind of physicalism this leaves him with is weak, he suggests that this very weakness is just the point. It signals his overthrowing of the presumption that the issue of fundamental importance in the philosophy of mind is the ontological one of establishing physicalism, and its replacement by the issue of determining the importance and value of mental vocabulary, given that it carries no ontological import.

Perhaps as a result of the influence of Quine's fervid physical realism, the philosophical value of a discourse was thought to be measured by its ontological credentials, which were in turn determined by its reducibility to physics: other discourses were thought to be fact-stating (and thus bona fide) just to the extent that they were reducible to the categories and laws of physics. An implication of this in the philosophy of mind was that one should advocate a physicalist theory of mind: if one is to avoid peddling in makebelieve, then one's theory of mind must be reducible (ultimately, ideally) to physics. ${ }^{13}$ This of course tied conceptual reduction to ontological reduction: reducibility to the terms of physics became the way of adjudicating on a discourse's reality-disclosing credentials, its capacity to be talking about anything real, and thus irreducibility to physics became the mark of discursive illegitimacy. It is this that later Davidson's "aontological" position contests: in separating conceptual and ontological reduction, and in making all events trivially "hunks of space-time," i.e., trivially events that can be talked about in terms of the categories of physics, he devalorizes the issue of ontological reduction (by taking it for granted), with the aim of redirecting our attention away from thinking it to be the one of prime importance in the philosophy of mind. In the final section I will turn to the issue of what the importance of mental discourse consists in, once it is divested of all ontological significance, but before doing so I will look at how Davidson's later position deflects the other traditional criticism of anomalous monism.

Unlike Kim who targets the (physical) monism of anomalous monism, Fodor targets the anomalousness. He argues that the lack of strict laws relating the mental to the physical makes the relation between the mental and the physical no different from the relation between, e.g., the geological and the physical (and more generally, the relation between the subject matter of any special science and the physical). Such special sciences do not arrive at strict laws but rather non-strict, ceteris paribus ones, yet, according to Fodor, these make for perfectly legitimate scientific laws and explanations, and the same is true of psychology. A psychophysical law, e.g., ceteris paribus everyone who likes an acorn 
omelet will eat one (Davidson, 1974: 233) is of the same form as the geological law, ceteris paribus a meandering river erodes its outside bank (Fodor, 1987: 5). Both are non-strict in that they require all kinds of provisos to be satisfied, or escape clauses to be written in, before they are even remotely capable of expressing a law-like relation. Just as the latter contains conditions like: provided that weather conditions do not change and the river does not freeze or dry up, or provided that a dam is not built to reduce the volume and pressure of water on the banks, or provided that the banks are not reinforced by steel, etc., etc.; so does the former whose ceteris paribus clause may include: provided that the omelet desirer does not believe the omelet is contaminated, or that he does not want to ruin his appetite, or that he has not gone vegan, and so on. Now, just as this does not undermine the scientific rigor and explanatory value of the geological law, neither, claims Fodor, should it the psychophysical law. For Fodor, psychology is analogous to geology and the other special sciences on this score: psychology arrives at psychological and psychophysical laws which are ceteris paribus laws with no less a claim to scientific rigor, predictive success and explanatory value with respect to intentional phenomena than the ceteris paribus laws of a special science, like geology, have with regard to geological phenomena.

18 Despite the fact that Fodor's strategy may well have the benefit of actually helping Davidson answer the previous criticism - for if laws governing the mental are no different in kind from those governing geological phenomena, and given that geological laws are not thought to compromise a robust physicalist account of geological phenomena then neither should psychological laws compromise the physicalism of mental phenomena either - the cost is that it would undermine the sui generis nature of the anomalousness of the mental, to which Davidson is still very much committed..$^{14}$ For Davidson, the reason why the anomalousness of the mental is different from the anomalousness of the geological (and indeed the anomalousness of the subject matter of any other special science) is, as we noted earlier, due to the constitutive role that normative rationality plays in intentional phenomena, as against the complete non-role it has in the constitution of geological, chemical, biological, etc., phenomena. This distinctiveness of the mental's anomalousness is expressed now not by his attempt at distinguishing strict and non-strict laws, which in turn forced a further distinction to be made between the non-strict laws of the special sciences and the non-strict laws of psychology (Davidson, 1970: 216-223 and 1993: 9-11) but by his distinguishing between the nature of psychological explanation and the nature of explanation in the special sciences. The anomalism of the mental is now something that shows itself in the distinctive nature of psychological explanation.

19 Before embarking on an account of what the value of mental vocabulary and the distinctiveness of psychological explanation consists in for later Davidson, it will be useful to sum up his position as it now stands in relation to his interlocutors. In order to do so, I will compare their respective attitudes towards a famous passage from Word and Object:

One may accept the Brentano thesis [of the irreducibility of intentional idioms to physical ones] either as showing the indispensability of an autonomous science of intention, or as showing the baselessness of intentional idioms and the emptiness of a science of intention. My attitude, unlike Brentano's, is the second. (Quine, 1960: 221)

20 What is interesting here is that Davidson, Brentano and Quine all agree that intentional phenomena in general cannot be reduced to, or read off, or inferred from, or 
nomologically aligned with, physical phenomena, but they each draw different conclusions from this. (Note that Fodor, unlike the other three, rejects the "Brentano thesis." He holds that mental phenomena can be nomologically aligned with physical phenomena in just the same way that geological phenomena, or the phenomena of other special sciences, can be nomologically aligned with physical phenomena). Brentano concludes: therefore, we need an autonomous science of the intentional, i.e., psychology (or for him, phenomenology). Quine concludes: therefore, so much the worse for intentional notions - get rid of them from our account of what is real (i.e., eliminative physicalism). But, Davidson's conclusion is different from both. He concludes: therefore, there is no science of psychology (contra Brentano), that psychology (the area of inquiry that investigates the intentional) cannot be a science, like the other natural or physical sciences. Psychology, though, for all that, is still a legitimate area of inquiry according to Davidson; it is just not science-like (contra Quine): it will not arrive at strict (or "strictenough") laws that predict and explain psychological phenomena by relating them to the underlying physical data in the way other sciences do. ${ }^{15}$ Davidson's position is that we should stop thinking of psychology as a science, stop thinking that it provides strict, or "strict-enough," laws, stop thinking that its ceteris paribus laws are no different from those of the special sciences (à la Fodor). But we should not think less of it because of this, nor think that because of this we should eliminate psychology from the bounds of legitimate discourse or "canonical notation" (à la Quine and the Churchlands), nor think that a view that embraces psychology's irreducibility to physics is crypto-dualism (à la Kim). Again, for Davidson, such a view is not dualist because of the separation of conceptual and ontological questions, and its failure at being a science is not something that needs to be apologized for. Instead of trying to show how it is science-like after all, later Davidson advocates discursive pluralism; i.e., he tries to show that reducibility to physics and modeling all explanation on so-called "hard" scientific explanation are not the only games in town. There are other forms of legitimate explanation that need to be recognized and saved from scientistic imperialism.

\section{The Importance and Value of Mental Vocabulary}

21 The issue that remains, of course, is: if the conceptual distinctness of mental vocabulary does not show up ontologically, if psychology does not talk about anything not already covered by neuroscience (and ultimately physics) why should it be preserved? What is the value or purpose of psychological descriptions that is lost, according to Davidson, even if, eliminating them (as Quine and the Churchlands advise) would not result in any loss in our ability to talk about anything that really exists? A clue can be given by concentrating on the value of the categories and concepts of a special science, e.g., geology, which is likewise strictly irreducible to physics yet shares its ontology with physics. However I want to emphasize at the outset that this analogy is double-edged, for while initially I will point to a similarity between psychology and geology, later I will point to a more important dissimilarity between them. First, though, the similarity: take the so-called law of geology, "Other things being equal, a meandering river erodes its outside bank," and suppose we try to reduce it to the categories that physics employs, by giving purely physical descriptions of all the myriad events and materials that constitute meandering rivers and eroding outside banks. Even supposing one could give an exhaustive physical description of all the possible ways in which rivers and banks could be instantiated across 
physical differences in liquid and bank composition, temperature and pressure conditions, etc., all of which would ultimately have to get analyzed into the favored terms of physics (say, sub-atomic particles and the laws governing them), what such a highly complex physical law would miss, apart from simplicity, is the way that the geological law can classify these very different (from a purely physical standpoint) events into kinds that are significantly alike in some way so as to all constitute events of meandering rivers and eroding outside banks. The physical descriptions by themselves provide no account at all of why these different occurrences should be grouped together as occurrences of the relevantly similar kinds that the law relates to, and also of why doing so is useful or valuable. This can only be achieved by employing the geological vocabulary for it discloses a significant pattern in the phenomena not captured in the diverse physical descriptions that pulls its weight explanatorily. It pulls its explanatory weight because its way of classifying events into kinds illuminates a significant relationship between events of one kind (windings of rivers) and events of another kind (wearings of banks). The value of the geological law is that while it does not unearth some new order of reality at the ultimate level of ontological composition, after all the geological phenomena it speaks of are all ultimately arrangements of sub-atomic physical stuff, nevertheless it discloses patterns in this fundamental physical stuff that are opaque to the basic physical descriptions themselves, but yet serve useful (to us) explanatory purposes, such as prediction and control of river bank erosion.

Similarly, psychological vocabulary serves to institute psychological kinds which enable us to identify and track explanatorily significant patterns in these otherwise physically describable phenomena but to which the physical descriptions are blind. Even if instances of these psychological kinds are identical with instances of certain physical kinds, this token identity to physical kinds will not explain what psychological kinds they belong to and why, nor will it capture the value of classifying events into these psychological kinds. As with the geological law, a psychological "law" such as "All things being equal, in the main someone who believes $p$ does not also believe not- $p$ " is a law that will detect similarities in kinds of mental states across a myriad of different contents realized in a multitude of physical ways. Left with just the physical descriptions of these mental states, one would have no way of understanding what it is about these variously different physical states that makes them belong to the same kinds (believings-that $-p$ that are not also believing-that-not- $p$ ) as well as what the value of classifying events into these kinds is.

So far I have used the analogy with geology to tease out a similarity between it and psychology; now I want to point out the important contrast between the geological and psychophysical "laws," from Davidson's perspective. The psychological "law's" difference from the geological law is that the patterns it discloses and traces are normative-rational patterns that are constitutive of the mental kinds disclosed and that seeing mental kinds as essentially normative-rational kinds pulls its weight explanatorily. It does so, though, not so much because it shows us that one kind of event (a believing-that- $p$ ) is not followed by another kind of event (a believing-that-not-p), although Davidson thinks it will do this in the main, but because it illuminates a basic, minimal condition on finding certain events to be contentful events or intentional states (i.e., psychological kinds) in the first place. Psychological descriptions classify events into significantly relevant kinds in virtue of normative principles of rationality, such that events so classified bear out normativerational relations with certain other events, and that they do is a condition of seeing 
these events as content bearing events at all. (Geological descriptions, of course, do not there is no requirement that river-meandering events bear normative-rational relations to bank-eroding events). The explanatory interest served by classifying some physical events into mental kinds according to normative-rational principles of classification is not the scientistic interests of prediction and control, but the hermeneutic interest of understanding. This explanatory interest gets us to see that what is important about some physical events - events that are also describable in mental terms - is not that they abide by laws that enable us to predict and control them, but that in being meaningmaking or understanding-embodying events constituted by norms of rationality, they express a way of understanding which demands a different mode of engagement if we are to come to grips with them, a mode of engagement that tries to appreciate, respect or understand the ways of understanding they embody, rather than one that tries merely to predict them.

Thus, the distinctness of the mental and why it is worth insisting on is not just that it allows us to discern kinds that are significant but which are opaque to purely physical descriptions (geological descriptions have this value as well as we saw); more importantly, it enables us to see that the value of the kinds it discerns is different from prediction and control, but involves instead understanding, or what Davidson calls (hermeneutic) charity. That the mental descriptions classify stuff into kinds that can also be described in physical terms, and thus that mental descriptions do not commit one to an ontology any different from what a purely physical vocabulary commits one to, is important only to the extent that it points to the fact that the distinctness of mental vocabulary lies elsewhere than ontology. What is important about insisting on the distinctness of mental descriptions from physical ones is that doing so enables us to recognize the different interests that these different vocabularies serve: the one prediction and control, the other understanding and rational respect, and that the second interest is of deep importance if we think it important to think of ourselves and others as meaning-carrying, understanding-embodying, rationally autonomous agents who demand understanding, hermeneutic charity, and rational recognition, rather than merely being causally determined or law-governed objects in need of prediction, manipulation and control.

In this way, the point Davidson is ultimately making in insisting on discursive pluralism and the irreducibility of intentional concepts is a Kantian one, and in this regard it is instructive to remember that even the early "Mental Events" is framed at beginning and end by passages quoted from Kant's Groundwork of the Metaphysics of Morals. Kant's project was to reconcile two competing images of human beings and their place in the world which emerged with the rise of the "new science" - the scientific (or naturalistic) image and the humanistic image. ${ }^{16}$ The scientific image depicts the world as a system governed by natural laws which describe the causal processes that exhaustively determine the behavior of all objects in the world. In this picture, human beings are thought of as natural objects just like any others in the world and as such our behavior is thought to be thoroughly determined by covering laws. The humanistic image, on the contrary, views human thought and action as normatively constrained, even rationally governed, not just causally determined. Of-course qua body, a human being is entirely a law-governed object - if I fall from a bridge I will accelerate downwards at the same rate as any rock, $9.8 \mathrm{~m} / \mathrm{s}^{2}$. However human thoughts and actions are not to be entirely understood as the causally determined movements of bodies. Unlike rocks and trees our actions are capable of being 
judged reasonable (or not) in light of the beliefs and desires we hold, and thus should not be seen entirely as the effects of antecedent, external causes. Similarly, the activity of thinking is not a purely causal or law-governed process: thoughts are not just causally related to each other, they are also normatively constrained, specifically by norms of reason expressed, inter alia, by logical laws or rules of inference. This humanistic image springs from the insight that human thought and action are subject to normative-rational governance and are thereby free, i.e., not purely causally determined. For Kant freedom and rationality are intimately connected: rationality, whether manifested theoretically in forming judgements and thoughts or practically in performing actions, requires freedom from causal determination. ${ }^{17}$

For Kant, then, normative rationality pervades human thought and action, and Davidson's similar insistence on the constitutive role that reason plays in his account of human thought and action is the central commonality he has with Kant. Kant characterizes the freedom or normative rationality of human thought and action in terms of the distinction between acting in accord with a rule and acting out of a conception of a rule (Kant, 1964: 397-399). Acting in accord with a rule is the type of behavior characteristic of natural objects and involves no recognition on the part of the object of the rule governing its behavior. Rocks do not recognize the validity of the law of gravity and on the basis of that recognition fall at the rate of $9.8 \mathrm{~m} / \mathrm{s}^{2}$; rather, they cannot help but act in accord with that natural law which is why it makes no sense to ask whether they should fall at that rate. ${ }^{18}$ Hence the rules that natural objects merely act in accord with are purely descriptive and predictive rules - they report how it is that objects have in fact behaved in the past and thus how they can be expected to behave in the future. However, thought and action done from a conception of a rule are not like this; they involve the agent's recognition of the validity of the rule and his thought and action conform to it on the basis of that recognition. Hence for creatures who can think and act out of a conception of a rule we can explain their action and belief under the aspect of its embodying an understanding (of the rule), or expressing a meaning that is the result of a self-conscious exercise of reason. To view humans as free in Kant's sense is to adopt this hermeneutic stance towards us, or in Davidsonian language, it is to have a charityaccording engagement with us, which is in turn to see our thinking and acting as constitutively normative-rational activities, activities for which it is appropriate to ask whether how we do in fact think and behave is how we should (given our understanding or rational self-consciousness). Furthermore, like Kant's distinction between causal determination and freedom, Davidson thinks of the distinction between the physical and the mental, or the natural and the normative, not as a distinction between two distinct kinds of things or substances (or in the terminology I've been using, not as an "ontological" distinction), but as a distinction between two different ways of describing or explaining thought and action (or what I've been calling a 'conceptual' distinction). ${ }^{19}$

Davidson writes at the end of "Mental Events," "The anomalism of the mental is thus a necessary condition for viewing action as autonomous" (Davidson 1970: 225). I take this to mean the following: that in explaining the freedom (autonomy) of human beings and their actions it is crucial to think of ourselves and others as subjects capable of recognizing norms of rationality and of responding to these norms on the basis of such recognition, rather than merely as objects that conform to laws (even if they are not entirely strict ones) external to themselves. Davidson's point is that as long as we think it important to think of ourselves and others as free in this Kantian sense, we should 
continue to think it important not to dispense with intentional psychological descriptions. In sum, Davidson is insisting that the distinctiveness, value and importance of mental descriptions consists in their pointing to, and safeguarding, this Kantian conception of ourselves as free; that such mental descriptions should not be eliminated if we are to do full justice to this conception. However, it is a conception of ourselves which is in danger of being lost if we concentrate, as late-twentieth century philosophy of mind does, on the scientistic issue of the ontological reduction of mind to body.

\section{BIBLIOGRAPHY}

DAVIDSON D., (1963), “Actions, Reasons, and Causes," repr. in Essays on Actions and Events, Oxford, Oxford University Press, 3-19.

DAVIDSON D., (1970), “Mental Events," repr. in Essays on Actions and Events, Oxford, Oxford University Press, 207-27.

DAVIDSON D., (1974), "Psychology as Philosophy," repr. in Essays on Actions and Events, Oxford, Oxford University Press, 229-44.

DAVIDSON D., (1985), “Replies to Essays X-XII," in Vermazen B. \& Hintikka M. eds., Essays on Davidson: Actions and Events, Oxford, Clarendon Press.

DAVIDSON D., (1987), "Problems in the Explanation of Action," repr. in Problems of Rationality, Oxford, Oxford University Press, 101-116.

DAVIDSON D., (1993), “Thinking Causes,” in Heil J. \& Mele A. eds., Mental Causation, Oxford, Clarendon Press, 3-17.

DAVIDSON D., (1999a), "Reply to Richard Rorty," in Hahn E. ed.,The Philosophy of Donald Davidson, Chicago, Open Court, 595-600.

DAvidson D., (1999b), “Reply to Bjørn Ramberg," in Hahn E. ed., The Philosophy of Donald Davidson, Chicago, Open Court, 619-21.

fENNELl J., (2010), “Re-Thinking Anglo-American Philosophy: the Neo-Kantianism of Davidson, McDowell, and Brandom," in May T. ed., History of Continental Philosophy, Vol. 8: Emerging Trends in Continental Philosophy, Durham, Acumen, 89-108.

FODOR J., (1987), Psychosemantics: The Problem of Meaning in the Philosophy of Mind, Cambridge (Mass.), MIT Press.

FODOR J. (1991), "You Can Fool Some of The People All of The Time, Everything Else Being Equal: Hedged Laws and Psychological Explanations," Mind 100, 19-34.

KANT I. (1964), Groundwork of the Metaphysics of Morals, trans. H. J. Paton, New York, Harper and Row.

KIM J., (1985), “Psychophysical Laws," in LePore E. \& McLaughlin B. eds., Actions and Events: Perspectives on the Philosophy of Donald Davidson, Oxford, Blackwell, 369-86. 
KIM J., (1993), “Can Supervenience and “Non-Strict Laws' Save Anomalous Monism?” in Heil J. \&

Mele A. eds., Mental Causation, Oxford, Clarendon Press, 19-26.

QUINE W. V. O., (1960), Word and Object, Cambridge (Mass.), MIT Press.

RAMBERG Bjørn, (2000), "Post-Ontological Philosophy of Mind: Rorty versus Davidson," in

Brandom R. ed., Rorty and His Critics, Oxford, Blackwell, 351-70.

SELlars W., (1963), "Philosophy and the Scientific Image of Man," in Science, Perception and Reality,

London, Routledge and Kegan Paul, 1-40.

\section{NOTES}

1. However by making the reason/cause (or law-like) and the mental/physical distinctions interchangeable in this context, I am not also suggesting that the mental/physical (and thus the reason/cause or law-like) distinction and the mind/body distinction are likewise intersubstitutable. As we shall see in the next section, that they should not be collapsed into each other is essential for understanding the kind of naturalism that Davidson advocates: the former distinction(s) is a conceptual distinction (a distinction in the way we describe or conceive things), the latter an ontological distinction (a distinction in the nature of the things themselves), and distinguishing between these two distinctions allows one to hold that mental talk is distinct from, or irreducible to, physical talk without this thereby requiring, or entailing, ontological dualism.

2. Reductive and eliminative naturalism are of course different: the former involves seeing the putatively non-natural (i.e., the normative) as really natural and so as not non-natural after all, while the latter involves seeing the normative as really non-natural but for this very reason advocates its elimination. At the end of the day, then, for both forms of naturalism there is nothing non-natural. It is this similarity in the conclusion they reach, rather than the different routes they take to reach it, that is of importance to me in characterizing Davidson's contrasting form of naturalism.

3. Davidson's difference from Quine in resisting the second form of naturalism is signaled by his according the principle of charity a constitutive role in interpretation, rather than a pragmatic role, as Quine does. To take the principle of charity as constitutive of the (attribution of) content of (to) mental states and sentences is to hold that the normative-rational principles that comprise it must generally apply to beliefs and believers: i.e., that something could not (be taken to) be a believer unless his/her beliefs accord with these principles for the most part. Thus, Davidson's theory of belief and meaning attribution gives an essential role to normative-rational considerations, for to insist that charity is constitutive of interpretation is just to insist that normative principles of rationality act as constitutive constraints on the (attribution of) meaning of (to) mental states and utterances. Incidentally, Davidson follows Quine in holding that all there is to the content of beliefs and the meaning of sentences is what can be got from our practices (i.e., radical interpretation or translation) of finding out about, giving, or attributing meaning and content. This entails that conclusions reached in radical translation/radical interpretation about meaning and content immediately carry a metaphysical sense as well as an epistemological one. Thus, the constitutivity of charity can be taken to express both an epistemological thesis (i.e., of setting out constraints that govern what it is to attribute beliefs or take someone to be a belief holder) and a metaphysical one (i.e., of setting out conditions that determine what it is to be a belief or believer). That radical translation and interpretation issue in conclusions that have simultaneously an epistemological and a metaphysical sense is what the use of parentheses in earlier sentences of this note is intended to capture. 
4. In Davidson's terminology: the irreducibility or ineliminability of the normative-rational character of the mental to the law-like character of the physical is its "anomalousness"; its avoidance of positing anything ontologically extra-physical or super-natural is its "monism."

5. I have elsewhere (Fennell, 2010) called this naturalistic position "neo-Kantian" since it insists on Kant's distinction between "ought" and "is," "norm" and "fact," "reason" and "cause." As such it highlights, in Kantian fashion, the indispensible role that reason must play in an adequate account of rational creatures like us and our rational activities of speaking a language and entertaining content-bearing mental states, while denying that this irreducibility requires the positing of a transcendent realm of Meanings or a domain of immaterial substances where such normative-rationality is to be housed. I further develop Davidson's connection to Kant in the final section of the paper.

6. This account of the relation between reasons and causes, which while distinguishing reasons from causes is careful not to entirely divorce them (and so precisely allows that reasons can be causes), is the centerpiece of his philosophy of action (Davidson, 1963). That a reason can be a cause of an action is what enables the distinction, crucial in that paper, between something's being $a$ reason for an action and its being the reason why the action was performed, which in turn is crucial to Davidson's account of the identity of an action. For example, I could perform the action of turning on the living-room light because I desire to find my car keys and believe turning on the light is a good way of satisfying this desire, or I could perform the action of turning the light on because I believe that there is a prowler in the yard and desire him to leave and believe that turning on the light will scare him away. Each belief-desire complex forms $a$ reason for turning on the light but which one is the reason for the action is determined by which one was the actual cause of the action, as a matter of fact. In this way that a reason can be a cause of an action is crucial to an intentional action's being the intentional action that it is: i.e., whether it is a trying-to-find-my-car-keys action or a trying-to-scare-off-a-prowler action.

7. It is problematic because while it guarantees that every event is physical (since every event can truly bear the physical description, e.g., "either was two stars colliding or was not two stars colliding"), it equally ensures that every event is mental (since every event can truly bear the mental description, e.g., "either was noticed by Jones or was not noticed by Jones"). This makes for obviously trivial senses of "mental" and "physical" since they can apply to every event, and it gives rise to a very trivial brand of physicalism: since all events are physical, all mental events are physical (thus it's a version of physicalism), but likewise, since all events are also mental, all (physical) events are mental. Thus the kind of physicalism it produces is just as much a kind of idealism.

8. Strictly, the anomalism of the mental involves the denial of psychological laws as well as psychophysical laws. However, since I am interested in what anomalism implies for mentalphysical relations, I will concentrate on its denial of psychophysical laws.

9. However, this token-identity does not entail that there are any general (type-) identities, or strict type-correlations, between events insofar as they are described in mental terms and those same events as they are described in physical terms - for the mental and the physical are conceptually distinct or anomalous for the reason given in the last section.

10. Note that this indifference towards ontological questions precisely results from psychological talk sharing its ontological commitments with physics, and thus is compatible with physicalism. It is in this sense that, as I remarked earlier, Davidson's later attitude of ontological indifference is formally compatible with his earlier physicalist position despite being very different in philosophical spirit.

11. Their view is that since mental terms do not refer to mental entities that really exists, such vocabulary belongs to a retrograde explanatory theory (folk psychology) that trucks in "makebelieve." As such, they argue it should be eliminated in favor of physical vocabulary, which does 
have real reference, and which does belong to a rigorous, scientific theory (e.g., neuroscience) that explains the phenomena in question more clearly and precisely.

12. This characterization is still present in the later writing, for in the "hunks of space-time" passage cited earlier, he says that what makes an event or object physical or biological or chemical or mental or political or religious or mythical, etc, is simply our using physical or chemical or biological (etc.) descriptions to talk about it. But in keeping with our a-ontological interpretation, it is evident from the passage that he thinks that engaging in such talk does not commit us ontologically to anything more than we are committed to by using the physical descriptions, so if we think that physics gives us the true account of what there is, in using these other descriptions we will not be talking about stuff that is not real. We will not be talking about stuff that is not physical (space-time hunks); rather we will be talking about that same physical stuff but in different language or under different descriptions. Thus, mental, or religious, or mythological, etc., talk has no ontological import.

13. The last part of this is certainly shared by Kim who thinks that there is no such thing as nonreductive physicalism - the only genuine physicalism, for him, is reductive physicalism.

14. Besides, Davidson thinks the cost is unnecessary since he thinks he already has a response to Kim's objection, as we have just seen.

15. Tellingly, the title of another seminal early paper of his in the philosophy of mind was "Psychology as Philosophy," rather than (presumably) "Psychology as Science."

16. This terminology is of course intended to evoke Sellars's distinction between the "scientific" and the "manifest" images of human beings, (Sellars, 1963: 1-40).

17. In fact, Kant tightly connects freedom, reason and morality. However freedom is not just required for moral action it is required for rational action generally (whether instrumental, prudential or moral). That is, moral action is a species of the genus: rational action, and this genus requires freedom from causal determination in the following way: if we are to think of ourselves as fully rational we cannot think of our actions as necessitated by our desires, past experiences, family influences, background, etc.. Instead we must freely choose which of those inclinations and desires are to govern our thoughts or actions, based on our conception of what we ought rationally to think or do. What distinguishes moral action as a special case of rational action is that in addition to requiring freedom from causal determination (i.e. acting out of a conception of what is the rational thing to do and imposing that on ourselves), it requires that our conception of the rational thing to do (that we freely impose on ourselves) has universal rational validity, that it is not just what is rational given some specific end or some particular conception of happiness, but what is rational überhaupt, irrespective of the particular ends or conceptions of the good life held by specific individuals or groups.

18. We can say, of course, that if the rock is dropped it should fall at $9.8 \mathrm{~m} / \mathrm{s}^{2}$, but the "should" here is not the "should" of normative-rationality. It expresses what we expect as a matter of fact to occur given our knowledge of physics; it is not a relation that should obtain independently of the physical facts. The point is that belief attribution on the basis of neural state activity has both "should" dimensions: not only should a believer, for example, hold the belief that $p$ if he holds the belief that $p$ and $q$ (in the sense that we expect the believer to, given our expectations and experiences of what believers as a matter of fact happen to believe in such a situation), but the believer should hold this belief in the sense that it is rationally required whether or not facts to do with belief-holding behavior bear this out.

19. The contemporary spin Davidson puts on all this is that the mental/physical distinction is not to be exactly aligned with the distinction between reason and cause but rather with the distinction between the rational and the causal or law-like (which is why I have taken pains to add this somewhat awkward hyphenation throughout). This is because Davidson wants his distinction to cover the contrast between natural-scientific and rational modes of explanation, and the notion of cause is no longer co-extensive with scientific laws, as nowadays scientific laws 
need not be thought of as strictly deterministic but can be probabilistic, e.g., quantum theory suggests a radical absence of causal determinism at the sub-atomic level.

\section{ABSTRACTS}

This paper argues that Davidson's position in the philosophy of mind undergoes a change from his early writings to his later ones. Whereas the early Davidson emphasizes how anomalous monism expresses a token-identity form of physicalism, his later writings instead suggest that anomalous monism articulates an "a-ontological" position. I aim to show both how the later aontological position results from Davidson's particular form of naturalism, which in his philosophy of mind gets expressed in the way he configures the mental/physical distinction as a conceptual as opposed to an ontological distinction, as well as how it provides him with new avenues of response to two influential criticisms anomalous monism has faced. I finish by explaining the Kantian significance that mental vocabulary has for Davidson in this a-ontological landscape.

\section{AUTHOR}

\section{JOHN FENNELL}

Grinnell College

fennellj[at]grinnell.edu 